\title{
CuOTf-mediated intramolecular diborene hydroarylation
}

Sunewang Rixin Wang, ${ }^{\mathrm{a}, \mathrm{b}}$ Merle Arrowsmith, ${ }^{\mathrm{a}, \mathrm{b}}$ Holger Braunschweig, ${ }^{\mathrm{a}, \mathrm{b}}$ Rian D. Dewhurst, ${ }^{\mathrm{a}, \mathrm{b}}$ Valerie Paprocki ${ }^{\mathrm{a}, \mathrm{b}}$ and Lena Winner ${ }^{\mathrm{a}, \mathrm{b}}$

Upon complexation to CuOTf, a $\mathrm{PMe}_{3}$-stabilized bis(9-anthryl) diborene slowly undergoes an intramolecular hydroarylation reaction at room temperature. Subsequent triflation of the B-H bond with CuOTf, followed by a $\mathrm{PMe}_{3}$ transfer, finally yields a cyclic $s p^{2}-s^{3}$ boryl-substituted boronium triflate salt.

By exploiting the Lewis-base stabilization strategy, several neutral diboron compounds with $\mathrm{B}-\mathrm{B} \pi$-bonding have been synthesized recently. ${ }^{1,2}$ Although these compounds electronically resemble olefins and alkynes, their energetically high-lying $\pi$ orbitals, and the inherently labile B-B bond, make these B-B multiple bonds easier to break, even with weakly donating or oxidising reagents, such as $\mathrm{CO}$, isonitriles, alkynes, and chalcogen-based oxidants. ${ }^{3}$ Undoubtedly, selective transformations of $B-B \pi$-bonds alone would be promising and highly desirable, in view of the ubiquitous use of olefins and alkynes in organic synthesis without the cleavage of the carbon skeleton. Thus far, only three types of such selective transformations of $B-B \quad \pi$-bonds have been reported: (i) coordination with transition metals or neutral Lewis bases; ${ }^{4,5}$ (ii) one- or two-electron oxidation without B-B $\sigma$-bond cleavage; ${ }^{6,7}$ and (iii) $\sigma$-bond addition, including hydroboration and hydrogenation. ${ }^{8,9}$

Recently, we successfully introduced the 9-anthryl group to diborane(4) chemistry. ${ }^{7 \mathrm{~b}, 10,11}$ Compared to mesityl and duryl groups, often used in diborane(4) chemistry, ${ }^{12}$ the planar 9anthryl substituent is in fact slightly smaller in size and bears neighbouring $\mathrm{sp}^{2}-\mathrm{C}-\mathrm{H}$ bonds rather than benzylic $\mathrm{sp}^{3}-\mathrm{C}-\mathrm{H}$ bonds, which may provide a new platform for diborane(4) chemistry. Similar to NHC-stabilized diborenes and diborynes, ${ }^{7 a}$ treatment of $\mathrm{PMe}_{3}$-stabilized 9-anthryl diborene 1 with elemental selenium gave diboraselenirane 2 . Interestingly, upon further exposure to elemental selenium, $\mathbf{2}$ was slowly converted to 1,9-diborylanthracene 3, effectively a "hydroarenolysis" of the B-B bond (Fig. 1, top). ${ }^{7 \mathrm{~b}}$ Inspired by this facile $\mathrm{sp}^{2}-\mathrm{C}-\mathrm{H}$ borylation with a $\mathrm{B}-\mathrm{B} \sigma$-bond, and the established fact that $\mathrm{C}-\mathrm{H}$ alkylation with olefins is easier than that with $\mathrm{C}-\mathrm{C} \sigma$-bonds, ${ }^{13}$ we considered the possibility of $\mathrm{C}-\mathrm{H}$ borylation with a B-B $\pi$-bond for diborane synthesis. ${ }^{14}$ While the $\mathrm{CuCl}$ complex of $\mathbf{1}$ is stable enough to be isolated, ${ }^{4} \mathbf{1}$ slowly undergoes intramolecular hydroarylation upon treatment with the more electrophilic species copper(I) triflate. The final

\footnotetext{
${ }^{a}$ Institut für Anorganische Chemie, Julius-Maximilians-Universität Würzburg, Am Hubland, 97074 Würzburg, Germany. E-mail: h.braunschweig@uni-wuerzburg.de ${ }^{b}$ Institute for Sustainable Chemistry \& Catalysis with Boron, Julius-MaximiliansUniversität Würzburg, Am Hubland, 97074 Würzburg, Germany

+Electronic Supplementary Information (ESI) available: Synthetic, spectroscopic and crystallographic details. CCDC 1575190-1575191. For ESI and crystallographic data in CIF or other electronic format see DOI: $10.1039 / x 0 x x 00000 x$
}

product 7, a cyclic $\mathrm{sp}^{2}-\mathrm{sp}^{3}$ boryl-substituted boronium triflate salt, may result from the hydroarylation intermediate 6 through tandem B-H triflation with CuOTf and a $\mathrm{PMe}_{3}$ transfer (Fig. 1, bottom). These results are reported in this Communication.

Initially, zinc(II) halides $\mathrm{ZnCl}_{2}$ and $\mathrm{ZnBr}_{2}$, known to be mild catalysts for Friedel-Crafts alkylation in organic synthesis, were tested for their ability to catalyze or mediate the intramolecular hydroarylation of diborene 1 . Suprisingly, monomeric 16electron $\pi$-complexes of $\mathrm{Zn}(\mathrm{II})$ were isolated from the benzene

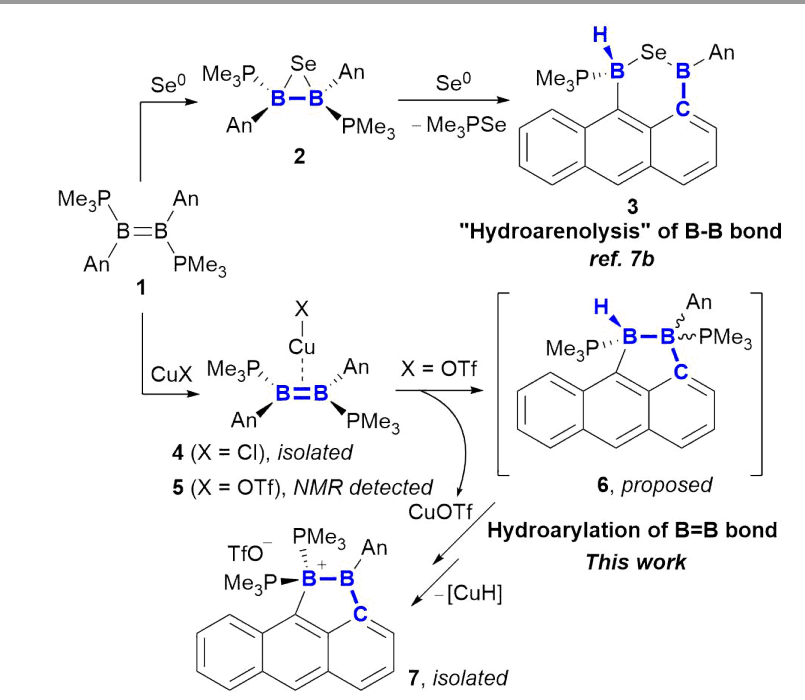

Fig. 1 Anthryl $\mathrm{C}-\mathrm{H}$ borylation with $\mathrm{B}-\mathrm{B}$ and $\mathrm{B}=\mathrm{B}$ bonds. $\mathrm{An}=9$-anthryl.

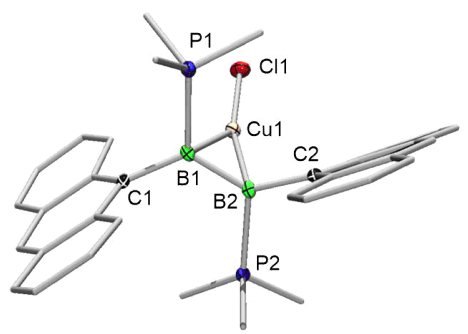

Fig. 2 Molecular structure of 4. Thermal ellipsoids are shown at the $50 \%$ probability level. Hydrogen atoms and solvent molecule (THF) are omitted for clarity. Selected bond lengths [Å] and angles [deg]: B1-B2 1.625(2), Cu1-B1 2.133(3), Cu1-B2 2.143(3); Cu1B1-B2 68.0(2), Cu1-B2-B1 67.3(2); $\Sigma \angle B 1357.9, \Sigma \angle B 2358.9$.

mixture, which were also stable in dichloromethane, ${ }^{4 d}$ a solvent commonly used for hydroarylation of olefins and alkynes. ${ }^{13,15}$ Attempts with the more electrophilic reagent zinc(II) triflate, however, gave no reaction as detected by NMR spectroscopy, possibly due to the bulkiness of the two triflate anions around $\mathrm{Zn}^{2+}$ ion.

Given the disappointing results with zinc, we then turned our attention to copper complexes to catalyse or promote 
intramolecular hydroarylation. ${ }^{16}$ A green solution of $\mathbf{1}$ in benzene immediately turned bright yellow upon mixing with excess $\mathrm{CuCl}$. As expected, ${ }^{4 b}$ the $\eta^{2}$-diborene complex 4 was isolated in $95 \%$ yield as a yellow solid and suitable single crystals for X-ray diffraction analysis were obtained from a THF solution at $-30{ }^{\circ} \mathrm{C}$ (Fig. 2). ${ }^{17}$ The solid-state structure of $\mathbf{4}$ is very close to that of reported for coinage metal complexes of NHC-stabilized diborenes, ${ }^{4 a, b}$ except for the more distorted metal center observed for 4 ( $\Sigma \angle \mathrm{Cu} 1355.6^{\circ}$ and $\mathrm{Cl} 1-\mathrm{Cu} 1-$ centroid(B1-B2) $\left.165.8^{\circ}\right)$. In the solution state, the ${ }^{11} B$ NMR signal for $4\left(\delta_{B}=17.1\right.$ $\left.\mathrm{ppm}, \mathrm{C}_{6} \mathrm{D}_{6}\right)$ is located slightly upfield with respect to that of the free ligand $\left(1: \delta_{B}=22.0 \mathrm{ppm}, \mathrm{C}_{6} \mathrm{D}_{6}\right)$, in accord with that observed for known coinage complexes. ${ }^{4 a, b}$ However, the broad ${ }^{31} \mathrm{P}\left\{{ }^{1} \mathrm{H}\right\}$ NMR signal is slightly downfield shifted $\left(4: \delta_{p}=-19.0 p p m, C_{6} D_{6}\right.$; 1: $\left.\delta_{P}=-21.3 p p m, C_{6} D_{6}\right)$, following the trend observed in $\mathrm{Zn}(\mathrm{II})$ and $\mathrm{Cd}(\mathrm{II})$ diborene complexes. ${ }^{4 \mathrm{~d}}$

To promote an intramolecular diborene hydroarylation reaction, complexation of $\mathbf{1}$ to (CuOTf) ${ }_{2}$ (toluene), a more electrophilic copper(I) reagent, was then conducted (Fig. 3). The

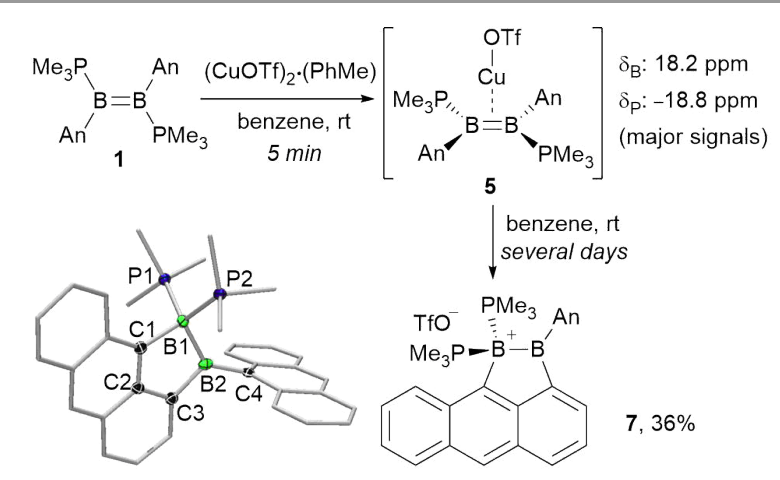

Fig. 3 Reaction of diborene 1 with (CuOTf) $)_{2}$ (toluene), and crystallographically determined structure of $\mathbf{7}$ (triflate anion not shown). An = 9-anthryl. Thermal ellipsoids are shown at the $50 \%$ probability level. Hydrogen atoms, solvent molecules (benzene) and anion are omitted for clarity. Selected bond lengths $[\AA \AA]$ and angles [deg]: B1-B2 1.782(2), B1-P1 1.948(3), B1-P2 1.960(2); P1-B1-P2 112.7(1), C1-B1-B2 98.6(2), B1B2-C3 103.5(2), B1-B2-C4 135.4(2), C3-B2-C4 121.0(2).

reaction was judged to be complete in several minutes as the characteristic green color of $\mathbf{1}$ in benzene immediately disappeared. Filtration to remove the generated black solids gave a bright red solution that showed an ${ }^{11} \mathrm{~B} N M R$ signal at $\delta_{B}$ $=18.2 \mathrm{ppm}$ (major) and a broad ${ }^{31} \mathrm{P}\left\{{ }^{1} \mathrm{H}\right\} \mathrm{NMR}$ signal at $\delta_{\mathrm{P}}=-18.8$ ppm (major), comparable to those for 4 and indicative of complex $\mathbf{5}$ as the major product. ${ }^{17}$ During storage in a glovebox for ca. one week at RT, a thin red mirror formed on the inner wall of the vial and orange block crystals precipitated, which were suitable for X-ray diffraction analysis. This confirmed the sample to be compound 7 , an unusual $\mathrm{sp}^{2}-\mathrm{sp}^{3}$ boryl-substituted boronium triflate salt (Fig. 3). ${ }^{18}$ The ${ }^{11} \mathrm{~B}$ NMR signals ( $\delta=103.1$ and $-20.5 \mathrm{ppm}$ ) are characteristic of $\mathrm{sp}^{2}-\mathrm{sp}^{3}$ diboranes, ${ }^{11 a}$ and the ${ }^{19} \mathrm{~F}$ NMR spectrum displays a singlet at $-79.0 \mathrm{ppm}$, in accord with a free triflate group. ${ }^{19}$ The ${ }^{31} \mathrm{P}\left\{{ }^{1} \mathrm{H}\right\}$ NMR spectrum shows broad multiplets at $\delta=-10.8 \mathrm{ppm}$ due to the coupling with both boron nuclei. Heating at $60{ }^{\circ} \mathrm{C}$ dramatically accelerated the transformation from 5 to 7 , as confirmed by ${ }^{11} \mathrm{~B} N M R$ and ${ }^{31} \mathrm{P}\left\{{ }^{1} \mathrm{H}\right\}$ NMR. ${ }^{17}$

Compound 7 may result from the initial intramolecular hydroarylation product 6 (Fig. 1) through a metathesis between the resulting $\mathrm{B}-\mathrm{H}$ bond and the released CuOTf, with the production of binary copper hydride, ${ }^{20}$ followed by a phosphine ligand transfer to the more electrophilic boron triflate. This metathesis could be initiated by the formation of a $\sigma-B-H$ copper(I) complex. ${ }^{21}$ Similar hydride abstractions from Lewis base-borane adducts were recently confirmed to form boronium cations in the dehydrogenation of dimethylamineborane catalyzed by a coordinatively unsaturated $\mathrm{Pt}(\mathrm{II})$ complex. $^{22}$

In conclusion, the CuOTf-mediated hydroarylation of a diborene is reported, providing a new method for diborane synthesis. The intermediate $\pi$-complex was detected by NMR spectroscopy and its $\mathrm{CuCl}$ analogue was isolated and structually determined by X-ray crystallographic analysis. In this boraFriedel-Crafts $\mathrm{C}-\mathrm{H}$ functionalization, the protic hydrogen of the $\mathrm{C}-\mathrm{H}$ bond is converted into a hydridic $\mathrm{B}-\mathrm{H}$ hydrogen, which further undergoes a metathesis with CuOTf to yield borane triflate. Thus, the reaction formally gives a difunctionalization product of a $\mathrm{B}=\mathrm{B}$ double bond. ${ }^{23}$

This project was funded by the European Research Council (ERC) under the European Union Horizon 2020 Research and Innovation Program (grant agreement no. 669054, to H. B.), and and the Alexander von Humboldt foundation (postdoctoral research fellowship to S.R.W.).

\section{Conflicts of interest}

There are no conflicts to declare.

\section{Notes and references}

1 (a) Y. Wang, B. Quillian, P. Wei, C. S. Wannere, Y. Xie, R. B. King, H. F. Schaefer, P. v. R. Schleyer and G. H. Robinson, J. Am. Chem. Soc., 2007, 129, 12412-12413; (b) $\mathrm{H}$. Braunschweig, R. D. Dewhurst, K. Hammond, J. Mies, K. Radacki and A. Vargas, Science, 2012, 336, 1420-1422.

2 (a) D. Scheschkewitz, Angew. Chem., Int. Ed., 2008, 47, 19951997; (b) Y. Wang and G. H. Robinson, Chem. Commun., 2009, 5201-5213; (c) H. Braunschweig and R. D. Dewhurst, Angew. Chem., Int. Ed., 2013, 52, 3574-3583; (d) H. Braunschweig and R. D. Dewhurst, Organometallics, 2014, 33, 6271-6277; (e) M. Arrowsmith, H. Braunschweig and T. E. Stennett, Angew. Chem., Int. Ed., 2017, 56, 96-115.

3 (a) H. Braunschweig, T. Dellermann, R. D. Dewhurst, W. C. Ewing, K. Hammond, J. O. C. Jimenez-Halla, T. Kramer, I. Krummenacher, J. Mies, A. K. Phukan and A. Vargas, Nat. Chem., 2013, 5, 1025-1028; (b) H. Braunschweig, T. Dellermann, W. C. Ewing, T. Kramer, C. Schneider and S. Ullrich, Angew. Chem., Int. Ed., 2015, 54, 10271-10275; (c) M. Arrowsmith, J. Böhnke, H. Braunschweig, M. A. Celik, C. Claes, W. C. Ewing, I. Krummenacher, K. Lubitz and C. Schneider, Angew. Chem., Int. Ed., 2016, 55, 11271-11275; (d) H. Braunschweig, I. Krummenacher, C. Lichtenberg, J. D. Mattock, M. Schäfer, U. Schmidt, C. Schneider, T. Steffenhagen, S. Ullrich and A. Vargas, Angew. Chem., Int. Ed., 2017, 56, 889-892; (e) W. Lu, Y. Li, R. Ganguly and R. Kinjo, J. Am. Chem. Soc., 2017, 139, 5047-5050.

4 (a) P. Bissinger, H. Braunschweig, A. Damme, T. Kupfer and A. Vargas, Angew. Chem., Int. Ed., 2012, 51, 9931-9934; (b) P. Bissinger, A. Steffen, A. Vargas, R. D. Dewhurst, A. Damme and H. Braunschweig, Angew. Chem., Int. Ed., 2015, 54, 43624366; (c) H. Braunschweig, T. Dellermann, R. D. Dewhurst, B. Hupp, T. Kramer, J. D. Mattock, J. Mies, A. K. Phukan, A. 
Steffen and A. Vargas, J. Am. Chem. Soc., 2017, 139, 4887-4893; (d) S. R. Wang, M. Arrowsmith, H. Braunschweig, R. D. Dewhurst, M. Dömling, J. D. Mattock, C. Pranckevicius and A. Vargas, J. Am. Chem. Soc., 2017, 139, 10661-10664.

5 J. Böhnke, H. Braunschweig, T. Dellermann, W. C. Ewing, T. Kramer, I. Krummenacher and A. Vargas, Angew. Chem., Int. Ed., 2015, 54, 4469-4473.

6 (a) P. Bissinger, H. Braunschweig, A. Damme, T. Kupfer, I. Krummenacher and A. Vargas, Angew. Chem., Int. Ed., 2014, 53, 5689-5693; (b) P. Bissinger, H. Braunschweig, A. Damme, C. Hörl and T. Kupfer, Angew. Chem., Int. Ed., 2015, 54, 359362.

7 (a) H. Braunschweig, T. Dellermann, W. C. Ewing, M. Hess, A. Rempel, C. Schneider and S. Ullrich, Angew. Chem., Int. Ed. 2016, 55, 5606-5609; (b) S. R. Wang, M. Arrowsmith, J. Böhnke, H. Braunschweig, T. Dellermann, R. D. Dewhurst, H. Kelch, I. Krummenacher, J. D. Mattock, J. H. Müssig, T. Thiess, A. Vargas, and J. Zhang, Angew. Chem., Int. Ed., 2017, 56, 8009-8013.

8 (a) H. Braunschweig, R. D. Dewhurst, C. Hörl, A. K. Phukan, F. Pinzner and S. Ullrich, Angew. Chem., Int. Ed., 2014, 53, 32413244; (b) H. Braunschweig and C. Hörl, Chem. Commun., 2014, 50, 10983-10985.

9 M. Arrowsmith, J. Böhnke, H. Braunschweig, M. A. Celik, T. Dellermann and K. Hammond, Chem. Eur. J., 2016, 22, 1716917172.

$10 \mathrm{H}$. Braunschweig, T. Brückner, A. Deißenberger, R. D. Dewhurst, A Gackstatter, A. Gärtner, A. Hofmann, T. Kupfer, D. Prieschl, T. Thiess and S. R. Wang, Chem. Eur. J., 2017, 23, 9491-9494.

11 (a) R. D. Dewhurst, E. C. Neeve, H. Braunschweig, T. B. Marder, Chem. Commun., 2015, 51, 9594-9607; (b) E. C. Neeve, S. J. Geier, I. A. I. Mkhalid, S. A. Westcott and T. B. Marder, Chem. Rev., 2016, 116, 9091-9161.

12 (a) R. Hunold, Ph.D. Thesis, University of Marburg, 1988; (b) A Moezzi, M. M. Olmstead and P. P. Power, J. Chem. Soc., Dalton Trans., 1992, 2429-2434; (c) H. Hommer, H. Nöth, J. Knizek, W. Ponikwar and H. Schwenk-Kircher, Eur. J. Inorg. Chem., 1998, 1519-1527.

13 (a) G. A. Olah, R. Krishnamurit, G. K. S. Prakash, Friedel-Crafts Alkylations in Comprehensive Organic Synthesis, B. M. Trost, I. Fleming, Eds., Pergamon: Oxford, UK, 1991. (b) Z. Nairoukh, M. Cormier and I. Marek, Nature Rev. Chem., 2017, 1, 0035.

14 I. A. I. Mkhalid, J. H. Barnard, T. B. Marder, J. M. Murphy and J. F. Hartwig, Chem. Rev., 2010, 110, 890-931.

15 V. P. Boyarskiy, D. S. Ryabukhin, N. A. Bokach and A. V. Vasilyev, Chem. Rev., 2016, 116, 5894-5986.

16 Copper-catalyzed hydroarylation of olefins and alkynes: (a) Y. Zhang, L. Chen and T. Lu, Adv. Synth. Catal., 2011, 353, 10551060; (b) Y.-L. Wang, W.-M. Zhang, J.-J. Dai, Y.-S. Feng and H.J. Xu, RSC Adv., 2014, 4, 61706-61710; (c) S. Ramesh and R. Nagarajan, Synthesis, 2015, 47, 3573-3582; (d) R. Jin, J. Chen, Y. Chen, W. Liu, D. Xu, Y. Li, A. Ding and H. Guo, J. Org. Chem., 2016, 81, 12553-12558.

17 See Supporting Information for experimental and spectroscopic details.

18 A diborane(6) monocation: O. Ciobanu, D. Emeljanenko, E. Kaifer, J. Mautz and H.-J. Himmel, Inorg. Chem., 2008, 47, 4774-4778.

19 D. A. Ruiz, M. Melaimi and G. Bertrand, Chem. Commun., 2014, 50, 7837-7839.

20 A. J. Jordan, G. Lalic and J. P. Sadighi, Chem. Rev., 2016, 116, 8318-8372.

21 Structurally authenticated $\sigma-\mathrm{B}-\mathrm{H}$ copper(I) complexes: (a) M. Shimoi, K. Katoh, H. Tobita and H. Ogino, Inorg. Chem., 1990, 29, 817-820; (b) A. E. Nako, A. J. P. White and M. R. Crimmin, Dalton Trans., 2015, 44, 12530-12534.

22 Hydride abstraction of amine-boranes via a $\sigma-\mathrm{B}-\mathrm{H} \operatorname{Pt}(\mathrm{II})$ complex: M. Roselló-Merino, J. López-Serrano and S. Conejero, J. Am. Chem. Soc., 2013, 135, 10910-10913.
23 Y. Shimizu and M. Kanai, Tetrahedron Lett., 2014, 55, 3727-3737. 


\section{TOC Entry:}

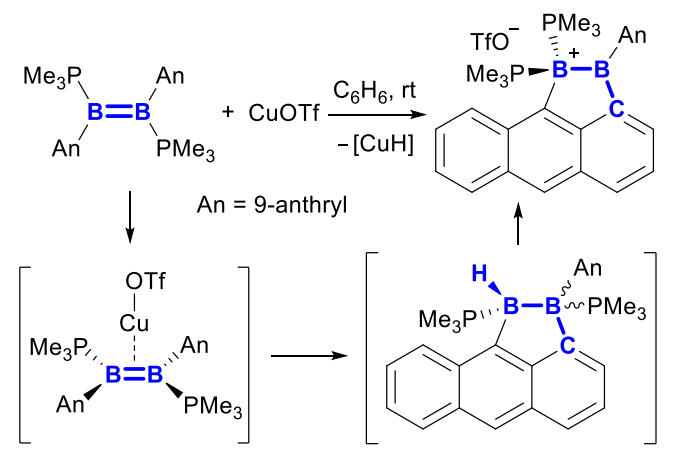

Text: CuOTf-mediated intramolecular diborene hydroarylation, followed by a $\sigma$-bond metathesis between the resulting $\mathrm{B}-\mathrm{H}$ bond and CuOTf, gives a cyclic $\mathrm{sp}^{2}-\mathrm{sp}^{3}$ boryl-substituted boronium triflate. 